\title{
Healthcare Governance Design in Blockchain
}

\author{
George Garritsen MSc MBA ${ }^{1} \&$ Jan Veuger BBA MRE PhD FRICS ${ }^{2}$ \\ ${ }^{1}$ PhD Candidate Blockchain Research Group Saxion University of Applied Sciences, Netherlands \\ ${ }^{2}$ Professor Blockchain, Leading professor Saxion Blockchain Institute, Saxion University of Applied Sciences \\ (UAS) Schools of Finance \& Accounting, School of Creative Technology, School of Governance, Law and Urban \\ Development \& Hospitality Business School, Netherlands \\ Correspondence: Jan Veuger, Saxion University of Applied Sciences (UAS) Schools of Finance \& Accounting, \\ School of Creative Technology, School of Governance, Law and Urban Development \& Hospitality Business \\ School, Netherlands
}

Received: May 27, 2020; Accepted: June 15, 2020; Published: June 22, 2020

\begin{abstract}
As a technology, Blockchain will make an important contribution to organizing differently within profit, nonprofit organizations and society. The aim of this reorganization is to reduce the pressure of regulation and work by digitally regulating the trust that is now often given by third parties. In addition, Blockchain goes over and through various processes, as a result of which third parties are no longer directly necessary due to the different organization of trust. What does organizing differently now mean for the use of coordination as a mechanism to steer organizations? This article, based on a thorough literature study will give an answer to this question. We looked at how coordination problems can be minimized by organizing it differently. Organizing differently here means no longer working from a central network but collaborating within a decentralized network with Blockchain as the technology. The interaction between the type of organization, the organizational policy, the processes, applications and infrastructure is essential in this respect, in which interoperability plays an important role. Blockchain ultimately contributes to reducing the response time of organizations, which in turn increases their adaptive capacity and therefore makes it possible to respond more quickly to changing market conditions, which are currently also occurring in the healthcare sector.
\end{abstract}

Keywords: Blockchain, health care, data, governance, organizations

\section{Introduction}

Blockchain is a new technology that can digitally transform processes inside and outside organizations and has an affect on coordination as a mechanism to steer organisations. What is a Blockchain now? In essence, Blockchain is a data structure - a kind of database - to which only digitally signed data can be added collectively by the peerto-peer network, without a central party (Goossens \& Verslype, 2019). In order to add digital data, there must be consensus within the network. According to Janse and Lin Lim, consensus means: 'obtaining a joint agreement between participating parties' (Janse \& Lin Lim, 2020). The aim of Blockchain is to use the consensus mechanism to reduce the coordination between organizations, so that the regulatory and workload within and also outside organizations is reduced. The Dutch Blockchain Coalition has defined Blockchain in its Dutch Blockchain Research Agenda as 'Blockchain is welcomed as a technology that allows us to organize our businesses, government and society in a radically different and decentralized way' (Delta, 2019).

\section{Governance and Control by Means of a Blockchain}

Mintzberg (Mintzberg, 1992) has described various coordination mechanisms that are used to link people and resources more closely together. Digital transformation concerns the impact that digital technologies and the digitization of business processes have on people, businesses and society (Aelen, 2016). Coordination is necessary to make the connection between people and resources. Digitization has an impact on the connection between people and resources. Blockchain is an example of a disruptive technology, which affects coordination and specifically the coordination mechanism. Blockchain is a good example where the coordination mechanism plays an important role in obtaining accurate and complete information about patients. In the current situation, not every healthcare provider has access to the same information regarding a patient's record. The patient file is personal and not public. In order to provide good and more efficient care, it is necessary to agree clear rules on ownership, management and access to health data. Blockchain can make an important contribution here to regulate these rules, 
because data is recorded in a decentralized and encrypted manner and is invariable. Blockchain contributes to the fact that every healthcare provider has access to the same information, which is up-to-date. An important starting point is that the patient is and remains the owner and manager of his own health data. The owner/manager gives permission to use his personal health data digitally. But what considerations can/must healthcare providers make with regard to governance and control when data management and transformation takes place via a Blockchain? Blockchain makes use of a decentralized network in which coordination is realized on the basis of consensus. Many healthcare providers still use a central network in which traditional coordination applies. What is the significance for the design, management and coordination when switching from a central to a decentralized network? In the following chapters the traditional governance and organization from a central network will be compared with that from a decentralized network. On the basis of this comparison, an answer can be given to the above question.

\section{Governance (Coordination and Steering) and Organization from a Central Network}

Mintzberg (Mintzberg, 1992) describes the link between 5 organizational units and 6 coordination mechanisms. This link results in seven forms of organization Table 1 shows the link between organizational units, forms of coordination and the characteristics of the organizational form in question (Olde Bijvank, 2020). When looking at healthcare, we are mainly dealing with a professional organization in which many of the organizational units involved are present. Standardization of skills is used as a coordination mechanism. This recognizes that the emphasis is on input management, in which important requirements are set for the knowledge and skills of the employee. The employee has room to act as he or she sees fit, which motivates him or her (Mintzberg, 1992). In addition, parts of Machinebureaucracy are also found in the health care sector where standardization of processes is used as a coordination mechanism (Mintzberg, 1992).

Table 1. Organizational form versus coordination mechanism, components and characteristics involved.

\begin{tabular}{|c|c|c|c|}
\hline Organizational form & $\begin{array}{l}\text { Coordination } \\
\text { mechanism }\end{array}$ & Organizational units involved & Features \\
\hline $\begin{array}{l}\text { The professional } \\
\text { organization } \\
\text { (decentralized } \\
\text { organizations) }\end{array}$ & $\begin{array}{l}\text { Standardization } \\
\text { of skills }\end{array}$ & $\begin{array}{l}\text { Top management, middle } \\
\text { management, executive, technical } \\
\text { and support staff. The core lies with } \\
\text { the executive framework. }\end{array}$ & $\begin{array}{l}\text { Strong degree of } \\
\text { cooperation } \\
\text { Input control, strict } \\
\text { requirements for } \\
\text { knowledge and skills, } \\
\text { room to act as you see fit }\end{array}$ \\
\hline
\end{tabular}

An important aspect within and between professional organizations concerns cooperation. What is meant by cooperation? Collaboration is understood to mean the coordinated activities of organizations (van Delden, 2009). If we look more specifically at what collaboration means in healthcare, the term is defined as follows: 'collaboration means that professionals are open to what the other person is doing and are aware of being part of the network around the patient. Collaboration is a necessity and can also be very satisfying' (Hammelburg, 2019). In order to be part of a network, activities need to be coordinated with each other. The concept of cooperation is important in order to be able to give good meaning to the design, management and coordination. Coordinating activities is an important aspect that requires coordination in order to achieve coherence. It is precisely coherence that leads to an increase in steering capacity and a reduction in coordination (van Delden, 2009). When using central networks, each organization still manages its own data and coordination often takes place in collaborative ventures. Where various healthcare providers and/or agencies work together from a central network, a coordination problem arises. This problem has to do with partial responsibility. Each participating party has only part of the resources and data at its disposal. The question is: "Who moves first?", "How do we know that the other party also participates"? "How are the costs and benefits divided among the participating parties? These questions arise and play a hampering role in increasing collaboration between healthcare providers (Berns, et al., 2019). This therefore hampers an unambiguous and correct exchange of information. If these questions are not clear and straightforward, this hampers important processes in healthcare. It is important that each participating party has full access to the resources and data, so that there is responsibility rather than partial responsibility. Blockchain as a technology has the ability to connect participating parties (healthcare providers) from a decentralized network. But what does this transition from a central network to a decentralized network mean for the organization, management and coordination of healthcare providers? Can the three questions that cause the coordination problem now be 
answered when working from a decentralized network, using Blockchain as a technology? The next section answers this question using desk research.

\section{Governance (Coordination and Steering) and Organization from a Decentralized Network}

The coherent model below, see figure 1, is used to clarify the structure of Governance from a decentralized perspective. The model actually consists of five layers. The first layer has to do with the type of organization and the coordination mechanism that steers the organization. This results in the organizational policy. The second layer relates to the processes. The processes provide information as output. To integrate Blockchain in this layer, the theory of Business Process Management is relevant. It is important that the same unit of language is spoken (Nictiz, 2017). This is also an important condition for eventually achieving interoperability. The fourth layer has to do with the applications. In terms of operability, these applications must be suitable to work within a Blockchain. The fifth layer concerns the IT infrastructure that serves as a precondition for optimal service provision. In the further course of this section, these layers will be further deepened.

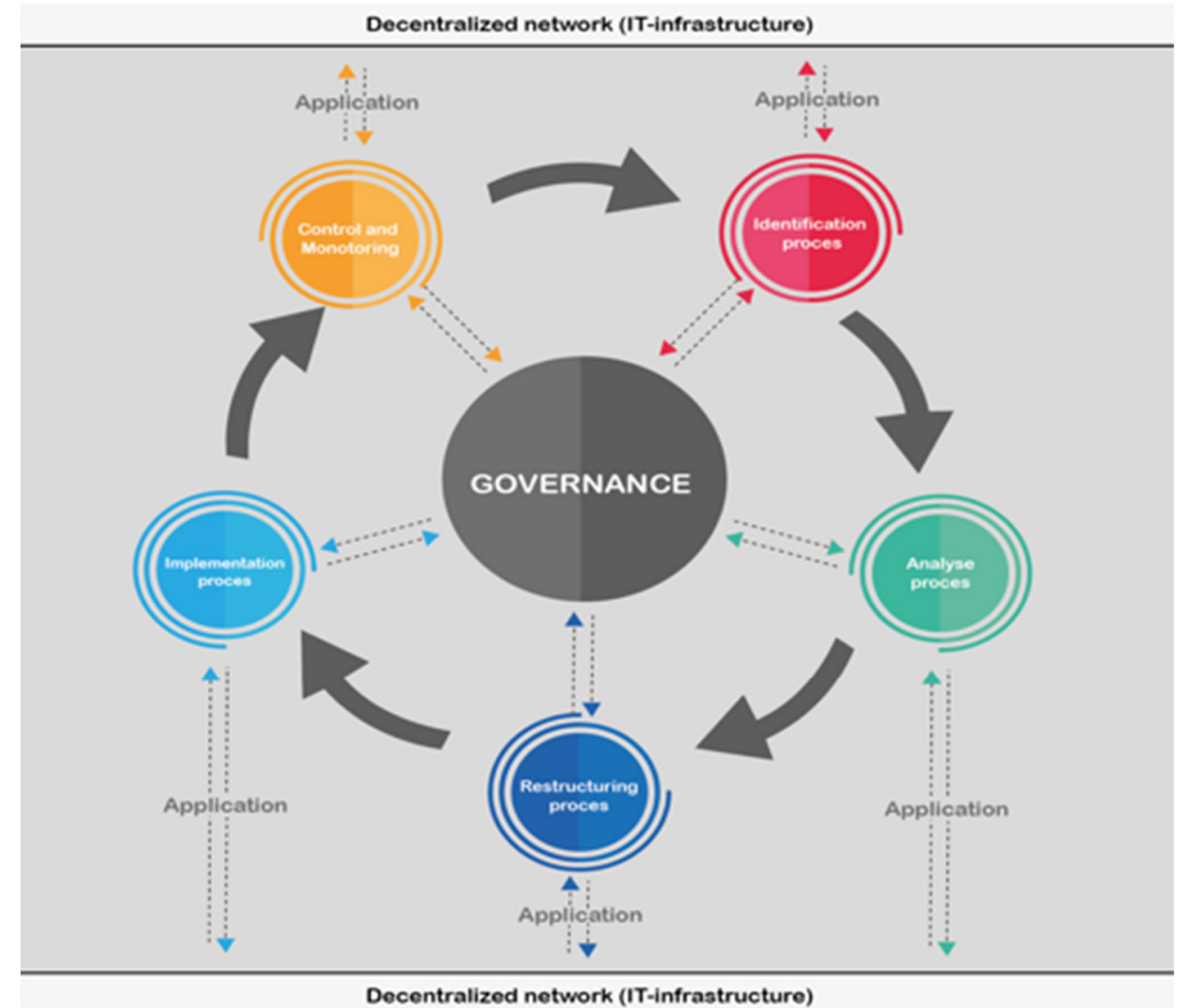

Figure 1. Coherent model structure Governance

Before considering the type of network, the frameworks should be formulated specifically for the care domain regarding the substantive values of care and the legal frameworks for governance at Blockchain in healthcare (Berns, et al., 2019). With regard to the values in healthcare, the most important aspects to be taken into account are the integrity (correctness, timeliness and confidentiality) and security of information and data. In addition, an important value is that the control of data lies with the citizen and that these data are transparent. The legal frameworks are important to take into account, but then it must be clear and straightforward what Blockchain is used for. (Berns, et al., 2019) If a Blockchain contains patient data, the regulations concerning the General Data Protection Regulation (avg) and the Dutch General Administrative Law Act should be properly applied when it comes to the automated application of decision-making rules. Once the values and legal frameworks have been outlined, the boundaries of the network should be considered. In order to be able to formulate the difference between a central and a decentralized network, it is necessary to clarify what a decentralized network is and what the difference is with a central network. In addition, it is important to include the objective of the organization in the selection process. 


\section{What is a Decentralized Network?}

This is a network that can exchange information or value directly and securely without the support of intermediaries (Janse \& Lin Lim, 2020). Blockchain as a technology provides the support. The difference is that in a decentralized network all stakeholders have the same data at their disposal and use the same resources. Both aspects contribute to obtaining coordination between activities (van Delden, 2009).

In order to work decentral, a choice has to be made about the boundaries of the network. Choices between a private, public network or a consortium are a prerequisite and depend on the content of the process for which the Blockchain is deployed. In addition to the choice of the type of decentralized network, a decision must be made for a 'permissioned' or a 'permissionless' network. With a 'permissionless' network, everyone has the possibility to validate data. A 'permissioned' network can only be validated by pre-selected shareholders (Veuger, 2019).

The choice for the network and the method of validation also determine the consensus mechanism to be used (Janse \& Lin Lim, 2020). There are various forms of consensus. For the various forms of consensus, reference is made to the Blockchain basic book (Janse \& Lin Lim, 2020, pp. 154-205). There are two distinct forms of consensus. The first is Proof of Work. Consensus is reached when $51 \%$ of the nodes grant permission to validate and is used in a permissionless network where access is public. This can be tested on the basis of the three questions already described if there is a coordination problem. Looking at these questions, in a public decentralized network it is difficult to clarify who is moving first, especially if there is a partial responsibility. It is also difficult to determine whether everyone participates in a public decentralized network that is permissionless. Agreements on the distribution of costs and benefits are difficult to make if it is not clear which parties are all participating. With a public decentralized permissionless network that has Proof of Work as a consensus, there is a good chance that a coordination problem will arise that will affect trust. On this basis, it can be stated that a public, decentralized permissionless network within healthcare is difficult to apply.

The second form of consensus in a decentralized network concerns the Proof of Stake. In a Proof of Stake, a (data) block is added based on a random selection process and the wealth (Janse \& Lin Lim, 2020). A random selection process is understood to mean that a selection is made without a reason (Onzetaal, 2017). Wealth is often defined as the number of coins a party owns. There are various forms of a Proof of Stake. These various forms are:

\section{Delegated Proof-of-Stake.}

2. Leased Proof-of-Stake.

3. Proof-of-Stake Velocity.

4. Proof-of-Authority.

The properties of these various forms are named in (Janse \& Lin Lim, 2020, pp. 154-166). The consensus mechanism Proof of Stake is mainly applied in a private Blockchain within a permissioned network. When looking at the different forms of Proof of Stake, the consensus mechanism 'Proof of Authority' is suitable on the basis of the properties. With a Proof-of-Authority it is known who validates and who is allowed to create new blocks (Janse $\&$ Lin Lim, 2020). Because there is a private Blockchain, there is clarity about the participating parties. Once again, the assessment can be done on the basis of three questions to see to what extent there is a coordination problem. In the case of a decentralized Permissioned network based on a consensus Proof-of-Authority, there is clarity as to who moves first, i.e. the party that validates and can add blocks to the network. Due to the fact that the network is permissive, it is also clear who 'moves along'. It is clear which parties are participating, because of the permissive nature of the network, so that agreements can be made in advance about the distribution of costs and benefits. The conclusion is that with a decentralized network permission based on a Proof-of-Authority the chance of coordination problems occurring is less. In order to give Blockchain projects (in which several authorities/parties are involved) in healthcare a chance of success, it is important to take this into account when making choices with regard to governance, and it is important to increase the influence of trust. What does this governance mean for the design of the Blockchain?

\section{Furnishing of the Blockchain}

With regard to the layout of the Blockchain, three levels can be used:

1. Blockchain platform (shared data environment).

2. Decentralized applications based on smart contracts (from citizen to professional to healthcare organization).

3. Decentralized hardware (with links to external systems for central databases and storage) (Goossens \& Verslype, 2019). 
Each level requires clarity about tasks, responsibilities and authority. It is important to be clear who the owners are, especially when it comes to partial responsibilities (Goossens \& Verslype, 2019). By making the link between the levels, the tasks, responsibilities and authorities, partial responsibilities are converted into an overall responsibility.

In addition to the design of the Blockchain, the consequences for the design of the processes also need to be considered. The theory of Business Process Management can be helpful in this respect. The goal of Business Process Management is that it adds value to an organization by improving processes (Dumas, 2013). Blockchain is a technology that not only automates processes but also leads to the creation of new processes. Blockchain technology is an opportunity for companies to improve business processes in a new way. (Milani, 2016). In order to integrate Blockchain properly, the current processes must be run through on the basis of the Business Process Management life cycle. This Business Process Management life cycle consists of the following components:

1. Identifying processes; it's about identifying the processes within the organization when they go beyond the boundaries of the organization.

2. Discovery of processes; It is about the data of processes and how these are recorded. This recording of obtained process data can be done by means of a central database, centralized network or a Blockchain, decentralized network.

3. Analyzing processes; When analyzing processes, problems can be identified that hinder the execution of tasks, responsibilities and authority. Blockchain can offer possibilities to provide new insights and also lead to the creation of new processes.

4. Restructuring of processes: A new design can be made for processes that form a bottleneck. Processes whose data cross borders must be redesigned by the organization involved.

5. Implementation phase: The newly designed processes must be implemented. The challenge in this phase is whether Blockchain can offer the necessary support to make the process between organizations run smoothly and remove the identified barriers.

6. Control and Monitoring: This is the final phase of the Business Process Management life cycle. When checking the data obtained from the Blockchain in particular, the problem arises that this is encrypted data (Milani, 2016).

There are major differences in the way in which data is recorded in healthcare. This has negative consequences for both the primary process and for quality registration and scientific research. To tackle this problem, unity of language is needed: unambiguous registration of data based on (inter)nationally available standards and systems.

\section{Interoperability}

Due to the fact that healthcare organizations work with different applications, it is important to also look at interoperability. What does interoperability mean? Interoperability means a network of different Blockchains that communicate and exchange data with each other (Janse \& Lin Lim, 2020). For organizations, public or private, when building Blockchain solutions, it is important that careful consideration is given to the limitation of the Blockchain and its flexibility. (Hewett, van Gogh, \& Palinczki, 2020, p. 10). When limiting the Blockchain, careful consideration should be given to the purpose of the Blockchain, given what the organization intends to achieve, whereby the frameworks are clear and unambiguous. The flexibility has to do with the possibility to connect with other platforms and ecosystems. Possibilities to approach Blockchains using apps also have consequences for flexibility. Scalability is also an important concept, especially in private blockchains. The more trust there is between the parties participating in a Blockchain, the more transparent the system becomes because all parties participate in obtaining consensus and can therefore validate real-time data, which ultimately has an impact on improving interoperability (Janse \& Lin Lim, 2020).

\section{Transmission of Data}

Data transmission can take place using a Blockchain platform. Participating parties have access to the platform and participate in the platform on the basis of the agreed governance. In order to achieve optimal operation of the platform, the concepts of limitation, flexibility and scalability are "important for the design of the governance".

Two forms of interoperability can be distinguished:

1. Digital Asset Exchange

2. Arbitrary Data Exchange 
With a Digital Asset Exchange, data transmission takes place via one Blockchain. An example of this is the payment from a Customer to a Supplier with bitcoins or other digital currencies using an Ethereum platform by means of a dApp.

In an Arbitrary Data Exchange the transmission takes place from one Blockchain to another Blockchain. One Blockchain provides information for another Blockchain. An Application Program Interface takes care of the transmission from one Blockchain to another Blockchain. For example, buyer A wants to obtain a digital warranty certificate on his products supplied by supplier B before payment is made.

Customer A first validates its warranty certificate on an Ethereum platform and the supplier only receives payment via a Hyperledger platform when the warranty certificate is validated by Customer A. An Application Programme Interface takes care of the transmission between the two Blockchain platforms. (Hewett, van Gogh, \& Palinczki, 2020). In the future, this form of interoperability will give more possibilities for cooperation between different parties and ultimately more third parties can be eliminated.

To achieve interoperability, stakeholders must have full confidence in the design and operation of the Blockchain platform (Hewett, van Gogh, \& Palinczki, 2020). In (Hewett, van Gogh, \& Palinczki, 2020, pp. 10-12) an interoperability model is worked out that is conditional for working with a Blockchain platform from different ecosystems, using a private Blockchain as a starting point. The starting point is that the governance between the ecosystems must be comparable. Data standardization only works if the stakeholders have confidence in each other. There must be clarity about responsibilities and powers. Consensus mechanisms between the Blockchains of the ecosystems should be the same. Smart Contracts must speak the same language to allow data to be transferred between Blockchain platforms. Furthermore, clear agreements must be made about the authorization and authentication of transactions. Multiple participants need to sign the same transaction from different platforms, making cross-verification necessary. With regard to the infrastructure, a private network is preferred, as it involves working from different ecosystems. This is due to higher performance in transaction processing and the ability to work from different geographical locations using the Internet. The challenge lies in finding similar characteristics between the Blockchains (Hewett, van Gogh, \& Palinczki, 2020).

\section{Social Relevance and Interests}

In this part of the article, the relevance of the above theory is demonstrated by means of two practical cases. The first case concerns the detection of fraud in the health care sector. The second case deals with the supply chain of protective equipment in the healthcare sector. Both cases show that a different way of working together offers opportunities to reduce coordination mechanisms.

In the Netherlands, the Healthcare Fraud Information Exchange (Informatie Knooppunt Zorgfraude, IKZ) registers the number of fraud cases in the health care sector. In 2018, the node received 558 signals of health care fraud (Zorgfraude, 2019). The following patterns of health care fraud can be recognized:

- Healthcare providers shift activities to another healthcare domain.

- Healthcare providers work within several care domains simultaneously.

- Care is declared at the expense of another care domain.

- Informal care is declared as formal care.

- Indications and requests within district nursing are too high and/or on false grounds.

- In the case of mental health care, oral care, more hours and/or treatments are declared than are provided.

- There are networks of suspected fraudulent organizations. They claim more care than has been provided within protected living, day care, paramedical care, personal care and individual guidance. This is often associated with insufficient quantity and quality of care. Some of the signals involve conspiracy with clients, and the recruitment and pressure of clients (care fraud, 2019).

Looking at the above patterns, it can be seen that several parties are involved, who work with mostly the same data and/or add data to the already available data. Currently, parties often work from a central network where it is difficult to use each other's data to achieve integration of data and joint solutions. Research into governance and organization on the basis of a decentralized network can form a basis for achieving integrated information exchange with the aim of seeing whether the complexity of processes can be reduced so that trust can be increased (Bessems \& Bril, 2017). The ultimate goal is to get a grip on fraud in healthcare. At present, health care fraud is mainly localized using the catch-re-catch method. This method involves comparing the registration of data from different databases to see whether the same data has also been recorded. A decentralized network where there is a 
single moment of registration and which is used by several parties, is a possible solution. Blockchain as a technology can play an important role in this.

With regard to the governance model, it is important that there is clarity regarding responsibilities and powers. (Jewbali, 2019). The Dutch Healthcare Authority could play an active role in this. Clear agreements on the choice of the Blockchain platform, the use of decentralized applications and hardware is an important condition with regard to the fulfilment of responsibilities and authorities. In addition, due to the sensitivity of the information, a permissive network with a consensus mechanism based on a Proof of Authority should be chosen. With regard to the set-up of the Blockchain, where it concerns the sharing of information about fraud, the consequences for the participating organizations with regard to the processes should be examined. The Business Process Management life cycle can be used to assess which processes need to be recalibrated in order to connect to a Blockchain platform.

In addition, when setting up the Blockchain, clear decisions need to be made about the limitation of the platform, its scalability and degree of flexibility. The limitation has to do with clarity and clarity on the part of all parties involved with regard to the objective, so that there is sufficient confidence to work with a platform where all relevant information about fraud from the organizations involved can be transmitted. Trust is necessary to realize a transparent platform that is also scalable as a result. Flexibility can actually be linked to interoperability. Where several organizations share information via one platform, interoperability will increase. Interoperability is achieved by setting up protocols so that data from different data silos can be transferred to the same format and placed on a platform (Nictiz, 2017). Finally, careful consideration must be given to the privacy sensitivity of the data made available on the platform. Certainly in healthcare, privacy is an important issue.

The ultimate goal of the Blockchain platform is to reduce all sorts of coordination mechanisms that currently exist with regard to fraud in the healthcare sector. Reducing the coordination mechanism requires a different way of working together.

\section{Supply Chain in Health Care}

Blockchain can also be of great value in the supply chain within the healthcare sector. Protective equipment is important in reducing a pandemic such as the Covid-19 virus. Healthcare organizations are confronted with uncertainties about the availability of the right protective equipment. There is insufficient insight at suppliers of protective equipment where protective equipment is still produced worldwide. There is also insufficient insight into whether protective equipment meets the required qualities. There is therefore a transparency problem and an integrity problem from the producer to the user. Blockchain can play an important role in solving both the transparency and integrity problem. It is important that there is full transparency throughout the entire supply chain. This means that products are traceable throughout the entire supply chain. This full traceability also makes it possible to identify where stocks are present. It is important that as many parties as possible participate within the Blockchain platform. Competitive considerations can be eliminated by not mentioning the identity of the competitor, but providing data about its stocks of products and the origin of the material with qualifications of the material. This can take place within a permissioned network. (Forum, 2020). This also increases the scalability of the Blockchain. Smart contracts play an important role within the various links of the supply chain. These Smart Contracts check by means of a algorithm whether conditions have been met. If a condition is met, a trigger is used to execute the transaction. Again, parties work with the same data and add data during the entire process. With regard to the set-up of the Governance, there should be clarity in the first instance with regard to the choice of the type of network.

The purpose of using the Blockchain should be clear to each of the participating parties. To this end, the limitation of the Blockchain solution should be answered. Interoperability will be an important issue, especially if different ecosystems are used. The interoperability model of (Hewett, van Gogh, \& Palinczki, 2020, pp. 10-12) indicates conditions that are decisive when setting up a Blockchain platform where multiple organizations can use it to gain insight into stocks, but also to be able to carry out transactions. Information originates from different ecosystems that have to cooperate with each other. In principle, this means that the governance of the ecosystems must be comparable. The ultimate advantage is that fewer coordination mechanisms are necessary within the entire supply chain, which results in a higher degree of effectiveness and efficiency by reducing transaction costs (Mintzberg, 1992).

Further research into the functioning of interoperability between different ecosystems is necessary to work on new solutions to problems such as those encountered today in the health sector. 


\section{Conclusion}

This article discusses the possibilities offered by Blockchain as a technology to reduce the regulation and workload within organizations by organizing differently. The healthcare sector is taken as an example. What does reorganizing mean for the use of coordination as a mechanism to steer organizations? To answer this question we looked at how coordination problems can be minimized by organizing it differently. Organizing differently here means no longer working from a central network but collaborating within a decentralized network with Blockchain as the technology. Three questions, which provide insight into the occurrence of a coordination problem, have been asked and elaborated for both a central and a decentralized network. It can be stated that a decentralized network causes fewer coordination problems. Looking at projects within the healthcare sector, in which cooperation between healthcare providers is an important aspect, it can be concluded that a permissioned decentralized network based on a Proof of Authority is a well-functioning mechanism. In addition, it is important that there is clarity in advance about the substantive values and the legal frameworks. In addition, careful consideration should be given to the structure of governance in order to achieve organizational steering and control. The interaction between the type of organization, the organizational policy, the processes, applications and infrastructure is essential in this respect, in which interoperability plays an important role. The relevance of this interaction has been described on the basis of two short cases. These cases relate to the use of Blockchain to combat fraud in healthcare and to increase insight into stocks and optimize transaction processing with regard to the supply chain for healthcare protective equipment.

\section{References}

Aelen, P. (2016, 11 17). Retrieved from https://www.ensie.nl/paul-aelen/digitale-transformatie

Beek van, D. (2018). De intelligente organisatie. In D. Beek van, De intelligente organisatie, continu verbeteren en innoveren met BI en Big Data (p. 353). Leusden: Passioned Publishers.

Berns, S., de Jong,, N., Oosterkamp,, H., Stolk, R., Wesseling, H., \& Wieringa, W. (2019). Naar werkende governance op Blockchain in de zorg. Berenschot.

Bessems, P., \& Bril, W. (2017). Blockchain Organiseren. Eindhoven: Mijnmanagementboek.

Delta, D. D. (2019). Retrieved from https://dutchblockchaincoalition.org/uploads/pdf/Dutch-BlockchainResearch-Agenda.pdf

Dumas, M. L. (2013). Introduction to Business Process Management. In M. L. Dumas, Fundamentals of Business Process Management (pp. 1-32). Heidelberg: Springer. https://doi.org/10.1007/978-3-642-33143-5_1

Forum, W. E. (2020, april 7). Retrieved from https://www.ledgerinsights.com/world-economic-forum-howblockchain-could-help-with-covid-19-supply-chain-disruption/

Goossens, J., \& Verslype, K. (2019). Blockchain en smart contracts. Tilburg: Tilburg University.

Hammelburg, R. L. (2019). Veranderende samenwerking in de zorg. Rotterdam: Springer Link.

Hewett, N., van Gogh, M., \& Palinczki, L. (2020). Inclusive Deployment of Blockchain for Supply Chains: Part 6 - A Framework for Blockchain Interoperability. Geneva, Switzerland: World Economic Forum.

Janse, A., \& Lin Lim, C. (2020). Basisboek Blockchain. In C. L. Janse, Basisboek Blockchain (pp. 154-166). Amsterdam: De boekdrukker.

Jewbali, L. (2019). Van gefundeerd vertrouwen naar gecodeerd vertrouwen? Een verkennend onderzoek naar het potentieel van Blockchaintechnologie bij Horizontaal Toezicht Zorg. Rotterdam: Horizontaal Toezicht Zorg.

Milani, F. G.-B. (2016). Blockchain and Business Process Improvement. BPTrends, 1-4.

Mintzberg, H. (1992). Structur in fives: Designing effective organizations. In H. Mintzberg, Structur in fives: Designing effective organizations. Upper Saddle River, NJ: Prentice Hall.

Nictiz. (2017). Blockchain in de zorg. Den Haag: Nictiz.

Olde Bijvank, S. (2020). Retrieved from http://www.house-of-control.nl/organisatiestructuren-mintzbergconfiguratie-coordinatiemechansimen-organisatietypen.html

Onzetaal. (2017, 3 24). Retrieved from https://onzetaal.nl/taaladvies/willekeurig- onwillekeurig/

van Delden, P. (2009). Samenwerking in de publieke dienstverlening. In P. van Delden. Delft: Eburon.

Veuger, J. (2019), Sole Editor Blockchain Technology and Applications. Peer reviewed (262 p.) Nova Science Publishers Inc. New York USA. May 2019. ISBN 978-1-53615-288-3. Retrieved from 
https://novapublishers.com/shop/blockchain-technology-and-applications/

Book reviews. Retrieved from https://novapublishers.com/shop/blockchain-technology-and-applications/

Veuger, J. (2020). Blockchain Convergentie. In J. Veuger, Blockchain convergentie, een nieuwe economie en samenleving met Blockchain (p. 84). Deventer: Saxion University of Applied Sciences.

Zorgfraude, I. K. (2019). Jaarbeeld 2018. Utrecht: Informatie Knooppunt zorgfraude.

Zorgfraude, I. K. (2019). Rapport Signalen orgfraude 2018. Utrecht: Informatie Knooppunt Zorgfraude.

\section{Copyrights}

Copyright for this article is retained by the author(s), with first publication rights granted to the journal.

This is an open-access article distributed under the terms and conditions of the Creative Commons Attribution license (http://creativecommons.org/licenses/by/4.0/). 